\title{
CXCL9 promotes prostate cancer progression through inhibition of cytokines from $T$ cells
}

\author{
SHANFENG TAN, KAI WANG, FUGUANG SUN, YANG LI and YISHENG GAO \\ Department of Urology, Linyi People's Hospital, Linyi, Shandong 276000, P.R. China
}

Received August 1, 2017; Accepted March 27, 2018

DOI: $10.3892 / \mathrm{mmr} .2018 .9152$

\begin{abstract}
Chemokines have been demonstrated to serve an important role in a variety of diseases, particularly in tumor progression. There have been numerous studies that have reported that $\mathrm{T}$ cells serve major roles in tumor progression. However, the function of CXC motif chemokine ligand 9 (CXCL9) in prostate cancer remains unknown. The present study aimed to investigate the role of CXCL9 in prostate cancer. A prostate cancer mouse model was generated by treating C57/BL-6 and B6.Cg-Selplgtm1Fur/J mice with 3,2'-dimethyl 4-aminobiphenyl (DMAB). Hematoxylin and eosin staining detected the histopathological alterations of mouse prostate tissues. Immunohistochemistry (IHC) staining determined cell proliferation of the mice. Flow cytometry was used to detect the alterations of $\mathrm{T}$ cells in $\mathrm{C} 57+\mathrm{DMAB}$ or CXCL9+DMAB mice. Immunofluorescence revealed that there was positive expression of interleukin-6 (IL-6) and transforming growth factor (TGF)- $\beta$ in the mouse tissues. The survival rates of C57+DMAB and CXCL9+DMAB mice was analyzed. The association of CXCL9 expression and clinical stages was also evaluated. Results revealed that prostate cancer pathology and cell proliferation in CXCL9+DMAB mice were significantly greater compared with the C57+DMAB mice. Compared with C57+DMAB mice, the number of $\mathrm{T}$ cells in peripheral blood and spleen of CXCL9+DMAB mice was significantly reduced. IHC demonstrated that the expression of IL- 6 and TGF- $\beta$ was significantly downregulated in the CXCL9+DMAB mice. The survival rate of CXCL9+DMAB mice was significantly decreased compared with the $\mathrm{C} 57+\mathrm{DMAB}$ mice. In addition, reverse transcription-quantitative polymerase chain reaction analysis demonstrated that CXCL9 mRNA expression in clinical samples was positively associated with clinical pathological stages of prostate cancer. In conclusion, CXCL9
\end{abstract}

Correspondence to: Dr Fuguang Sun, Department of Urology, Linyi People's Hospital, 27 East of Jiefang Street, Linyi, Shandong 276000, P.R. China

E-mail: fguangsun@163.com

Key words: CXC motif chemokine ligand 9, T cell, interleukin-6, transforming growth factor- $\beta$, prostate cancer may promote prostate cancer progression via inhibition of cytokines from $\mathrm{T}$ cells.

\section{Introduction}

Prostate cancer is a malignant tumor that occurs in prostate tissue, which is the result of abnormal dysplasia of prostate acinar cells. In regions such as Europe and the United States, prostate cancer is the most common male malignancy; the mortality rate has exceeded lung cancer. The incidence of prostate cancer has gradually increased with the arrival of China's aging population and the extension of life and diet changes (1). It is also known that prostate cancer-associated fatalities frequently occur in patients with metastatic castration-resistant prostate cancer. Although several novel drugs for castration-resistant prostate cancer have been approved, each of these has prolonged survival by just a few months. Therefore, novel treatments of prostate cancer are required to extend life expectancy even further.

Currently, immunotherapy has been reported to be an effective treatment for cancer patients (2). Several strategies, including cancer vaccines and immune checkpoint inhibitors, have been investigated in clinical studies for cancer patients (3-5). However, T cell immunotherapy of prostate cancer is still at an early stage of clinical development. It has been reported that several molecules are potent $\mathrm{T}$ cell checkpoint inhibitors which reverse immunologic tolerance in many types of cancer, including prostate cancer (6). Therefore, the molecules which serve crucial roles in $\mathrm{T}$ cell activity during prostate cancer may be useful for the treatment of this disease. CXC motif chemokine ligand 9 (CXCL9) is a chemokine, which regulates the host's response to inflammation by recruiting leukocytes to the inflammatory environment. Chemokines serve important roles in immune responses of the body. Chemokines are expressed by almost all monocytes, neutrophils, eosinophils and natural killer (NK) cells but are expressed to a lesser degree by macrophages, B cells and $\mathrm{T}$ cells (7-9). It has been reported that the absence of CXCL9 affects leukocyte migration and tissue infiltration (10). As CXCL9 has the ability to interact with a variety of ligands, it serves a certain biological role in the inflammatory response. In addition, inflammation is closely associated with the occurrence and development of tumors $(11,12)$. The present study aimed to investigate the effect of CXCL9 on T cells in prostate cancer. 


\section{Materials and methods}

Clinical data. Prostate cancer tissue specimens $(\mathrm{n}=37)$ were obtained between July 2014 and December 2015 from Linyi People's Hospital (Linyi, China), from patients aged between 35 and 68 years who were diagnosed with prostate cancer without any therapy. These tissue samples were collected with the consent of the patients. The study was approved by the Medical Ethics Committee of the Linyi People's Hospital. The clinical stages of the patients were clarified according to the tumor nodes metastasis staging system. Adenoma $(n=3)$, Stage 0/I ( $(n=8)$, II ( $n=10)$, III $(n=12)$ and IV $(n=4)$.

Mice, cell and prostate cancer models. C57BL/6 black mice ( 8 weeks old; male $\mathrm{n}=25$; female $\mathrm{n}=25$; weight $\sim 20-25 \mathrm{~g}$ ), were purchased from Sun Yat-sen University Experimental Animal Center (Guangzhou, China) and were used as control mice. A total of four B6.Cg-Selplgtm1Fur/J mice, (8 weeks old; male $\mathrm{n}=2$; female $\mathrm{n}=2$; weight $\sim 20-25 \mathrm{~g}$ ), which highly express CXCL9, were purchased from Jackson Laboratory (Ben Harbor, ME, USA). In total, 54 mice were used in this study. They were maintained under specific pathogen-free conditions with 12 -h light $/ 12$-h dark cycles at $26-28^{\circ} \mathrm{C}$ and $50-65 \%$ humidity and a normal diet (including $4 \%$ fat and $0.07 \%$ cholesterol) and water ad libitum.

DMAB (3,2'-dimethyl 4-aminobiphenyl), was used as a chemical carcinogenic agent. The mice were enrolled and initiation with subcutaneous injection of DMAB $(150 \mathrm{mg} / \mathrm{kg}$ b.w.) once a week for 3 weeks to construct the prostate cancer model. The mice were anesthetized by $10 \%$ chloral hydrate solution $(3 \mathrm{ml} / \mathrm{kg}$, Sigma-Aldrich; Merck KGaA, Darmstadt, Germany), and then the blood samples were collected. Then the mice were sacrificed by cervical dislocation, and the prostate tissues were collected and stored. Animal experiments were approved by the Medical Ethics Committee of Linyi People's Hospital.

Hematoxylin-eosin $(H \& E)$ staining. The prostate tissues of each mouse were fixed using $10 \%$ formalin at room temperature for $24 \mathrm{~h}$. Subsequently, the tissues were cut into paraffin sections $(5 \mu \mathrm{m})$ and stained with hematoxylin for $5 \mathrm{mins}$ and eosin for $30 \mathrm{sec}$ at room temperature, mounted in a $50 \%$ glycerol solution in distilled water to prevent autofluorescence (Mikrochem, Bratislava, Slovak Republic) and evaluated with an Axiophot microscope (Zeiss, Oberkochen, Germany; magnification, $x 400$ ) equipped with a CELLscan System (Scanalytics; BD Biosciences, Franklin Lakes, NJ, US).

Immunohistochemistry. Immunohistochemistry was performed according to a conventional protocol (13). The paraffin-embedded prostate tissue sections were incubated in a dry oven at $63^{\circ} \mathrm{C}$ for $1 \mathrm{~h}$. De-paraffinization and rehydration were then performed. The sections were incubated with 30-50 $\mu 1$ anti-IL-6 (SAB3300071), anti-TGF- $\beta$ (SAB4502958) and anti-PCNA (WH000511M2) antibodies (dilution 1:100; Sigma-Aldrich; Merck KGaA) overnight at $4^{\circ} \mathrm{C}$. The sections were washed with PBS buffer three times, each time for $5 \mathrm{~min}$. A total of 30-50 $\mu$ l HRP conjugated IL-6 (A0192), TGF- $\beta$ (A0277) and PCNA (AF1363) secondary antibodies (1:1,000; Beyotime, Shanghai China) was added to the tissue section and incubated at $37^{\circ} \mathrm{C}$ for $1 \mathrm{~h}$. The sections were washed with PBS buffer three times, each time for $5 \mathrm{~min}$. Excess liquid was dried around the tissue and then placed flat into the moist chamber. A working solution of 3,3'-diaminobenzidene (30-50 $\mu 1$; Sigma-Aldrich; Merck KGaA) was added to the sections and incubated at room temperature for 1-5 min. After the color was developed, the sections were rinsed with distilled water to stop the reaction. A positive results was defined as the presence of staining in $10 \%$ or more of cells. The stained tissue sections were reviewed and scored separately by two pathologists blinded to the clinical parameters.

Flow cytometry. Blood samples were collected from different mouse organs, such as, orbital cavity $(1 \mathrm{ml})$, caudal vein (50-100 $\mu \mathrm{l})$, spleen (30-50 $\mu \mathrm{l})$ and bone marrow (80-120 $\mu \mathrm{l})$. Then red blood cell lysis buffer (Beyotime Institute of Biotechnology, Shanghai, China) was added to the blood samples, and centrifuged at $350 \mathrm{xg}$ for $5 \mathrm{~min}$ at $4^{\circ} \mathrm{C}$. The supernatant was discarded and the bottom part of the precipitation was washed with $0.5 \%$ bovine serum albumin (BSA; Beyotime Institute of Biotechnology) 3 times at room temperature, each time for $5 \mathrm{~min}$. Anti-CD4-FITC antibody (F1773; 1:100; Sigma-Aldrich; Merck KGaA) was added in the dark and incubated for $30 \mathrm{~min}$ and centrifuged at $350 \mathrm{xg}$ for $5 \mathrm{~min}$ at $4^{\circ} \mathrm{C}$. The supernatant was discarded and the precipitation was washed 3 times with $0.5 \%$ BSA, the supernatant was removed and the precipitation was re-suspended in $200 \mu \mathrm{l}$ $0.5 \%$ BSA. The protein was detected using FACSCanto $^{\mathrm{TM}}$ II (Becton Dickinson, Franklin Lakes, NJ, USA).

Immunofluorescent staining. The prostate tissue was fixed with $4 \%$ formaldehyde for $15 \mathrm{~min}$ at room temperature, then washed 3 times with PBS before permeabilization with $0.2 \%$ Triton X-100 (PBS) for $10 \mathrm{~min}$, also at room temperature. The paraffin-embedded tissue sections were deparaffinized in xylene and rehydrated in a graded series of ethanol solutions and then incubated for $20 \mathrm{~min}$ in $3 \% \mathrm{H}_{2} \mathrm{O}_{2}$ to quench the endogenous peroxidase activity. Next, the sections were heated in target retrieval solution (Dako; Agilent Technologies, Inc., Santa Clara, CA, USA) for $15 \mathrm{~min}$ in a microwave oven (Oriental Rotor, Tokyo, Japan) to retrieve the antigen. Subsequently, the sections were blocked with $2 \%$ BSA at $4^{\circ} \mathrm{C}$ for 15 min (D3308; Beyotime Institute of Biotechnology) and incubated with CD4+ (AF1792) and CD8+ (AF1417) primary antibodies (1:100; Beyotime Institute of Biotechnology) overnight at $4{ }^{\circ} \mathrm{C}$, and stained with a fluorescein-conjugated secondary antibody anti-CD4+-FITC antibody (F1773) and anti-CD8+-FITC antibody (F0772; 1:100; Sigma-Aldrich; Merck KGaA) for $2 \mathrm{~h}$ at room temperature. Finally, images were captured with Leica SP5 AOBS confocal microscope (Leica Microsystems GmbH, Wetzlar, Germany), and the number of positive cells and field area ratio were calculated with Image J software version 1.48 (National Institutes of Health, Bethesda, MD, USA) (14).

Western blotting. Tissues were lysed in Laemmli sample buffer (Bio-Rad Laboratories, Inc., Hercules, CA, USA) with a protease inhibitor, complete EDTA-free (Roche Diagnostics $\mathrm{GmbH}$, Mannheim, Germany). The protein lysate sample was extracted from tumor tissue of mice, and then centrifuged 
A
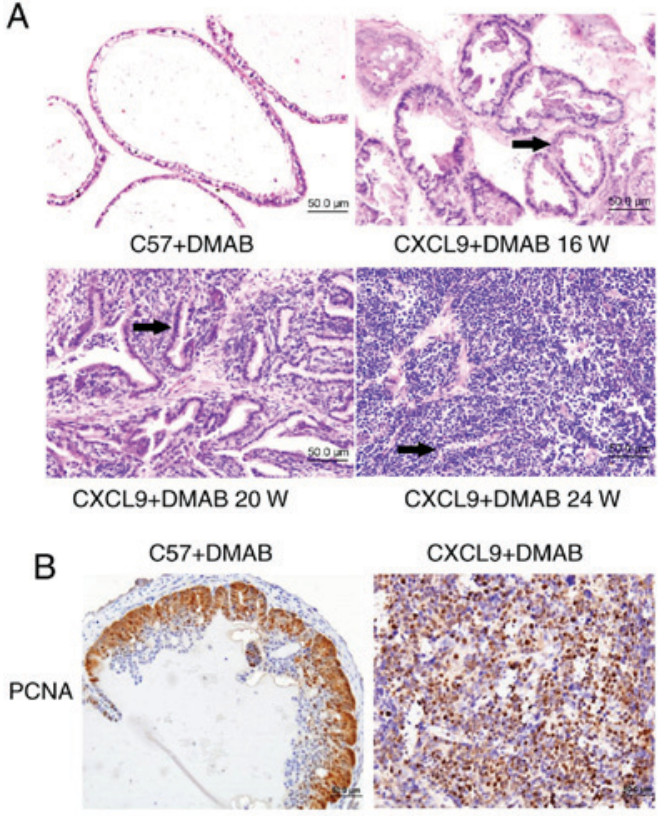

Figure 1. CXCL9 gene overexpression promotes the pathological process of prostate cancer in mice. (A) Hematoxylin eosin staining was used to detect histological alterations in two models of chemically induced mice at different time points $(0,16,20$ and 24 weeks; magnification, $x 400)$ (B) Immunohistochemical staining of PCNA was used to detect cell proliferation in the two models (magnification, $\mathrm{x} 400$ ). CXCL9, CXC motif chemokine ligand 9; DMAB, 3,2'-dimethyl 4-aminobiphenyl; PCNA, proliferating cell nuclear antigen.

at $12,000 \mathrm{x}$ for $10-15 \mathrm{~min}$ at $4^{\circ} \mathrm{C}$. The supernatant was collected, and the protein concentration was measured using BCA Protein Assay Kits (Pierce; Thermo Fisher Scientific, Inc., Waltham, MA, USA). The protein sample were electrophoresed on $10 \%$ polyacrylamide gels (Bio-Rad Laboratories) and transferred to Immobilon-PSQ polyvinylidene difluoride membranes (EMD Millipore, Billerica, MA, USA). Then the membrane was blocked in $2 \% \mathrm{BSA}$, at $4^{\circ} \mathrm{C}$ for 15 min with TBS containing 5\% skimmed milk and $0.1 \%$ Tween-20, and incubated with the anti-IL-6 (SAB3300071) and anti-TGF- $\beta$ (SAB4502958) antibodies (Sigma-Aldrich; Merck KGaA) at $4^{\circ} \mathrm{C}$ overnight. Finally, the membrane was incubated with HRP conjugated IL-6 (A0192) and TGF- $\beta$ (A0277) secondary antibodies (1:1,000; Beyotime Institute of Biotechnology) at room temperature for 50-90 $\mathrm{min}$. The protein was visualized using an enhanced chemiluminescence reagent (Bio-Rad Laboratories, Inc., Hercules, CA, USA). The proteins were semi-quantified using Image J software version 1.48 (National Institutes of Health).

Reverse transcription-quantitative polymerase chain reaction $(R T-q P C R)$. Total RNA was extracted from prostate tissues of the patients by using TRIzol reagent (Invitrogen; Thermo Fisher Scientific, Inc.). Reverse transcription was performed with random primers using the First Strand cDNA Synthesis kit (Takara Biotechnology Co., Ltd., Dalian, China). RT-qPCR was performed with SYBR-Green PCR Master mix (Thermo Fisher Scientific, Inc.). PCR cycles were run on the iCycler IQ Multi-color Detection system (Bio-Rad Laboratories, Inc.) and the cycling conditions were $95^{\circ} \mathrm{C}$ for $30 \mathrm{sec}, 1$ cycle; $95^{\circ} \mathrm{C}$ for $5 \mathrm{sec}$ and $62^{\circ} \mathrm{C}$ for $20 \mathrm{sec}, 40$ cycles. The primers used for amplification were: CXCL9 F, 5'-AGGGTCGGCTGTTCC TGCATC-3' and R, 5'-TTCACATCTGCTGAATCTGGG TTTA-3'; GAPDH F, 5'-GCACCGTCAAGGCTGAGAAC-3' and R, 5'-TGGTGAAGACGCCAGTGGA-3'. Relative expression level was calculated using the $2^{-\triangle \Delta C q}$ method (15). GAPDH was employed as an endogenous control. The data analysis was performed based on the sample threshold cycle $(\mathrm{Ct})$ value from three independent experiments.

Statistical analysis. All data were analyzed using SPSS version 19.0 statistical software (IBM Corp., Armonk, NY, USA). The results of immunohistochemistry were analyzed by Image Pro Plus software version 1.48 (Media Cybernetics, Inc., Rockville, MD, USA). $\mathrm{P}<0.05$ was considered to indicate a statistically significant difference. One-way analysis of variance was conducted followed by Bonferroni method as a post hoc test for multiple comparisons. Kaplan-Meier survival plots were generated and comparisons were constructed with log-rank statistics. $\mathrm{P}<0.05$ was considered to indicate a statistically significant difference.

\section{Results}

High expression of the CXCL9 gene promotes the pathogenesis of prostate cancer mice. In order to determine whether CXCL9 overexpression affects the pathogenesis of prostate cancer in mice, prostate cancer was induced in C57BL/6 (C57) and B6.Cg-Selplgtm1Fur/J (CXCL9-overexpressed) mice. H\&E staining (Fig. 1A) revealed that the prostate cancer pathology of CXCL9-overexpressed mice was significantly greater than C57 mice and CXCL9-overexpressed mice had developed differentiated adenocarcinoma at 20 weeks. The nuclear staining was significantly greater, the ducts were irregular and glandular cavity became smaller (black arrows). At 24 weeks, CXCL9-overexpressed mice exhibited a clear pathology of prostate cancer with a neuroendocrine differentiation phenotype (Fig. 1A). Therefore, the mice at 24 weeks were selected for subsequent experiments. Immunohistochemical staining (magnification, $\mathrm{x} 400$ ) of proliferating cell nuclear antigen (PCNA) revealed that proliferation levels in CXCL9+DMAB mice were increased compared with C57+DMAB mice (Fig. 1B). The aforementioned results suggested that CXCL9 overexpression serves an important role in promoting progression of prostate cancer and accelerates the pathogenesis of prostate cancer.

High expression of CXCL9 inhibits T cell activation. As chemokines serve an important role in the tumor microenvironment, it was hypothesized that CXCL9 regulates T cell-mediated immunity. The present study examined the alterations of $\mathrm{T}$ cells in peripheral blood and spleen in C57+DMAB mice and CXCL9+DMAB mice. The results showed a reduction in the number of $\mathrm{T}$ cells in peripheral blood and spleen of CXCL9+DMAB mice compared with C57+DMAB mice (Fig. 2A) (Q4 quadrant). The infiltration number of $\mathrm{T}$ cells in tumor tissues was also examined in CXCL9+DMAB mice and C57+DMAB mice. The results suggested that high expression of CXCL9 significantly inhibited T cell infiltration into the tumor microenvironment (Fig. 2B). Based on the above findings, it was hypothesized that CXCL9 may regulate the 

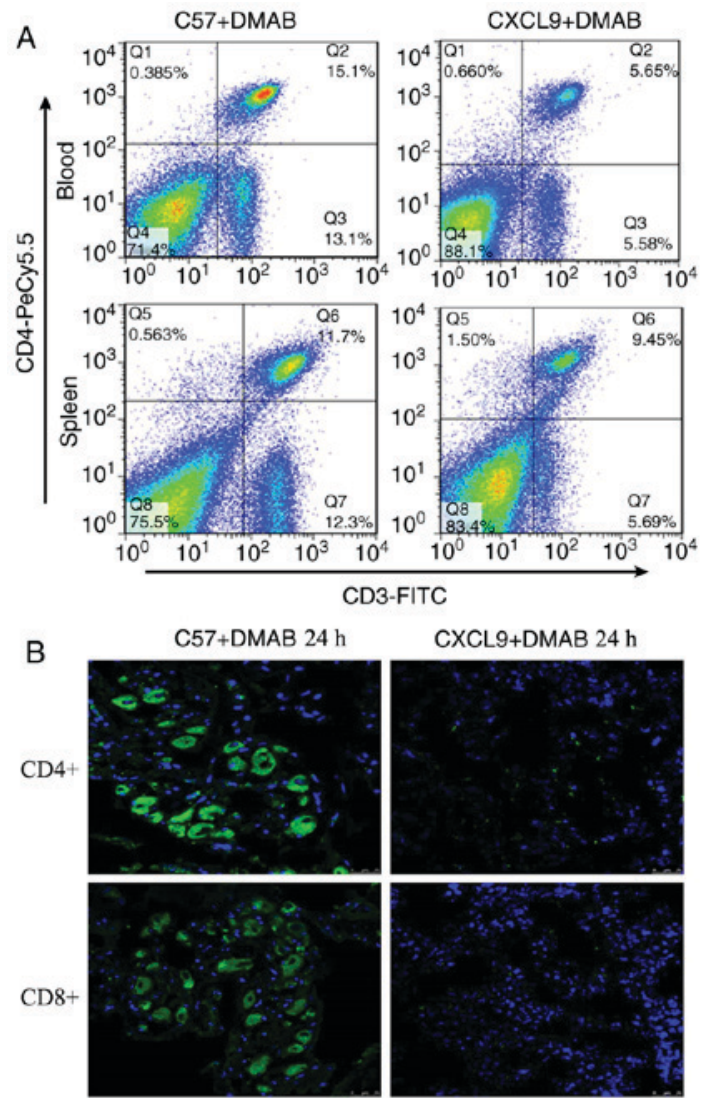

CXCL9+DMAB $24 \mathrm{~h}$

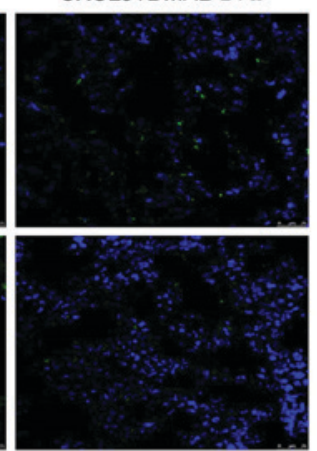

Figure 2. High expression of CXCL9 inhibits T cell activation. (A) Flow cytometric analysis of T-cells in the spleen and blood leukocyte in C57+DMAB and CXCL9+DMAB groups (magnification, x400). (B) Immunofluorescence detection of white blood cell expression in two models of mice (magnification, x400). CXCL9, CXC motif chemokine ligand 9; DMAB, 3,2'-dimethyl 4-aminobiphenyl.

progression of prostate cancer either directly or indirectly by influencing the number of $\mathrm{T}$ cells infiltrated in immune organs and the tumor microenvironment.

CXCL9 inhibits the secretion of IL- 6 and TGF- $\beta$ from $T$ cells. In order to verify whether CXCL9 overexpression affects the cytokines secreted in the tumor microenvironment, the expression levels of IL- 6 and TGF- $\beta$ in the prostate tissues were examined. The results demonstrated that high expression of CXCL9 downregulated the levels of IL-6 and TGF- $\beta$ in tumor tissues compared with C57+DMAB mice (Fig. 3A and B). Therefore, it was concluded that CXCL9 reduced the secretion of IL- 6 and TGF- $\beta$ via the reduction of the number of $\mathrm{T}$ cells in immune organs and the tumor microenvironment, and promoted the development of prostate cancer.

High expression of CXCL9 accelerates the pathogenesis of prostate cancer. To address the association between CXCL9 overexpression and progression of prostate cancer, the survival rates of $\mathrm{C} 57+\mathrm{DMAB}$ mice and $\mathrm{CXCL} 9+\mathrm{DMAB}$ mice were measured. The results suggested that the survival rate of CXCL9+DMAB mice was lower than C57+DMAB mice (Fig. 4A). In addition, the mRNA expression levels of CXCL9 in clinical samples were measured. The mRNA levels of CXCL9 in patients at stage III was greater than at stage II $(\mathrm{P}=0.024)$,
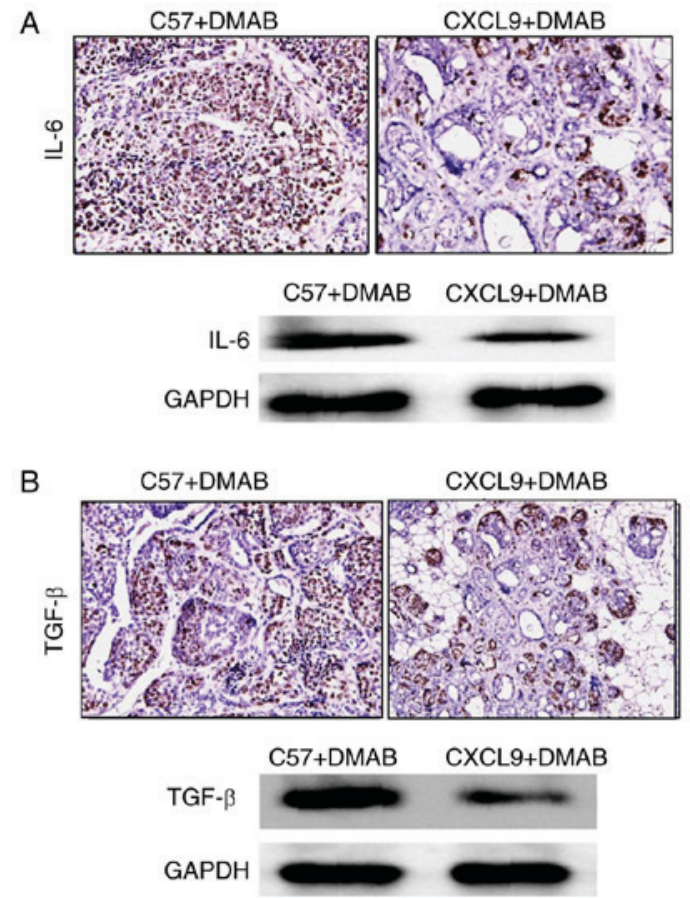

Figure 3. CXCL9 inhibits the secretion of IL- 6 and TGF- $\beta$ from T cells (A) Detection of IL-6 expression by immunohistochemistry and western blotting (magnification, $x 400$ ), and (B) detection of TGF- $\beta$ expression by immunohistochemistry and western blotting in $\mathrm{C} 57+\mathrm{DMAB}$ and CXCL9+DMAB groups (magnification, $x 400$ ). CXCL9, CXC motif chemokine ligand 9; IL-6, interleukin-6; TGF- $\beta$, transforming growth factor- $\beta$; DMAB, 3,2'-dimethyl 4-aminobiphenyl.
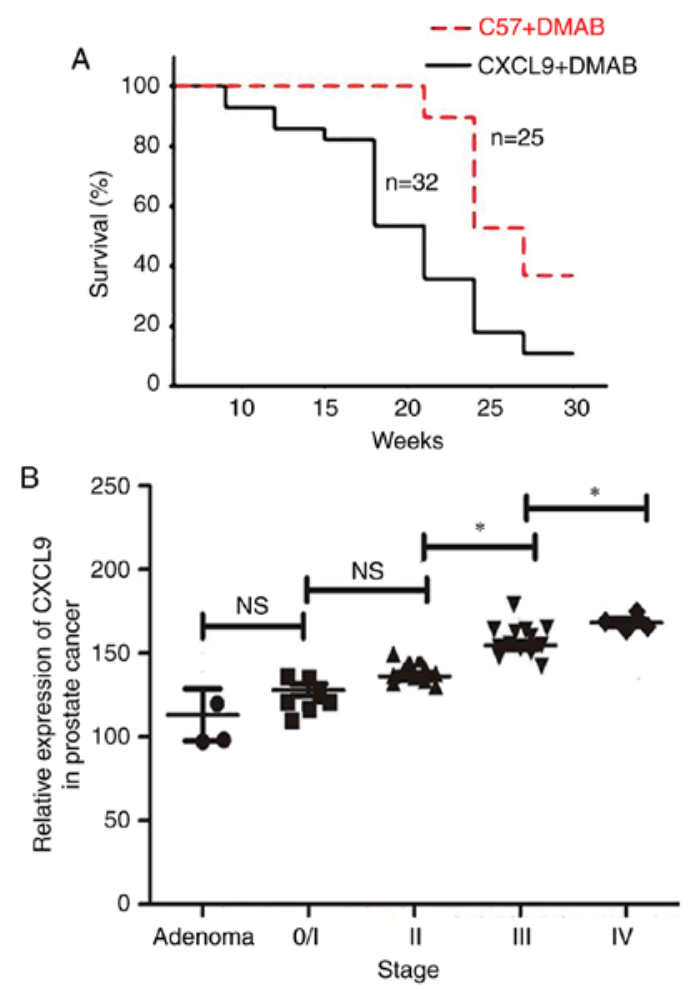

Figure 4. High expression levels of CXCL9 accelerates the pathogenesis of prostate cancer. (A) Survival analysis of C57+DMAB and CXCL9+DMAB mouse groups. (B) Reverse transcription-quantitative polymerase chain reaction of CXCL9 expression levels in clinical samples at different clinical stages (adenoma, n=3; 0/I, n=7; II, n=11; III, n=10; IV, n=6). "P<0.05. ns, not significant; CXCL9, CXC motif chemokine ligand 9; DMAB, 3,2'-dimethyl 4-aminobiphenyl. 
and the mRNA levels of CXCL9 in patients at stage IV was greater than at stage III $(\mathrm{P}=0.012)$. The results suggested that the mRNA expression levels of CXCL9 were positively associated with clinical staging (Fig. 4B).

\section{Discussion}

Prostate cancer is a highly malignant tumor with complex pathogenesis. Abnormal expression levels of chemokines have been identified in prostate cancer (16). Many chemokines may have inhibitory effects on the tumor, and certain chemokines may promote tumor progression (17). Several chemokines, including CXCL4 and CXCL10, have been used in translational medicine (18). In a previous study, an association between CXCL9 and cancer was demonstrated; however, the effect of CXCL9 in prostate cancer has not been reported. A previous studies revealed that CXCL9 is highly expressed in human digestive organs, such as gastrointestinal organs, however the expression of CXCL9 in developmental organs has not been studied (19). In the present study, CXCL9-overexpressed mice and C57 mice were selected for investigation. Chemical induction was used to induce prostate cancer in the mice, and it was demonstrated that CXCL9 may serve an important role in promoting tumorigenesis. In addition, the effect of inhibition or knockdown of the CXCL9 gene in tumorigenesis is important to fully illustrate the effect of CXCL9. However, a limitation of the present study was that these experiments were not performed due to the difficulty of gene knock-out mouse construction; however, this will be investigated in further studies.

The underlying mechanism of CXCL9 in promoting the pathogenesis of prostate cancer was investigated in the present study. Chemokines serve an important role in the tumor microenvironment, and it was hypothesized that CXCL9 serves an indirect role in affecting white blood cells. The results suggested that the $\mathrm{T}$ cells in the spleen were significantly reduced in CXCL9+DMAB mice. A previous study reported that CXCL9 regulates the homing of lymphocyte thymus and affects $\mathrm{T}$ cell maturation (20). In the tumor mouse model, the function of CXCL9 in regulating $\mathrm{T}$ cell maturation and reducing the number of $\mathrm{T}$ cells requires further investigation. IL-6 is produced by activated T cells and has anti-tumor effects. The anti-tumor biological activity of IL-6 primarily includes: (i) Promoting the proliferation and killing activity of $\mathrm{NK}$, and promoting $\mathrm{NK}$ cells to secrete interferon and express the IL-1 receptor agonist chain; (ii) inducing lymphocyte-activated killer cells, which may dissolve a variety of tumor cells $(21,22)$. The present study demonstrated a reduction in the number of $\mathrm{T}$ cells in peripheral blood and spleen in CXCL9+DMAB mice compared with C57+DMAB mice.

TGF- $\beta$ is a cytokine secreted by immune cells and has the ability to inhibit tumor cell growth and induce tumor degeneration $(23,24)$. Studies have revealed that the anti-tumor effect of TGF- $\beta$ depends on its secretion by $\mathrm{T}$ helper $1 \mathrm{CD}$-positive cells to inhibit tumor growth and angiogenesis in receptor-interacting serine/threonine protein kinase (RIP)-Tag2 model mice (25). A mouse model where the RIP promoter may be controlled has been obtained from the hybridization of RIP-Tag 2 model mice and LMCV mice. It has been demonstrated that CD8-positive T cells serve an important role in inhibiting tumor growth (26). The present study concluded that T cells and expression levels of IL-6 and TGF- $\beta$ were reduced by increased levels of CXCL9, resulting in enhanced growth of tumors in hybrid mice. CXCL9 overexpression reduced the number of $\mathrm{T}$ cells in immune organs and the tumor microenvironment, and reduced the secretion of IL- 6 and TGF- $\beta 2$, and thereby promoted the development of prostate cancer.

It was observed that the survival rate of CXCL9-overexpressed mice was significantly reduced compared with C57 mice. Therefore, the targeted inhibition of CXCL9 expression may be applied in a clinical setting. RT-qPCR detected the mRNA expression of CXCL9 in prostate cancer patients at different pathological stages, and the results revealed that the mRNA expression levels of CXCL9 were positively associated with clinical staging in clinical samples, suggesting that the patients with high expression of CXCL9 exhibited more advanced pathological features.

In conclusion, the present study suggested that expression of CXCL9 in prostate cancer is associated with clinical stage. CXCL9 may inhibit the expression of IL- 6 and TGF- $\beta$ in prostate cancer model mice, however the underlying regulatory mechanism of the development of prostate cancer requires further investigation.

\section{Acknowledgements}

Not applicable.

\section{Funding}

No funding was received.

\section{Availability of data and materials}

The datasets used and/or analyzed during the current study are available from the corresponding author on reasonable request.

\section{Authors' contributions}

ST and YG conceived and designed the experiments; ST, FS, YL and YG performed the experiments; ST, KW and YG analyzed the data; ST, KW, FS and YG contributed reagents/materials/analysis tools and ST and YG wrote the manuscript.

\section{Ethics approval and consent to participate}

Animal experiments were approved by the Medical Ethics Committee of Linyi People's Hospital.

\section{Patient consent for publication}

These tissue samples were collected with the consent of the patients and the study was approved by the Medical Ethics Committee of the Linyi People's Hospital.

\section{Competing interests}

The authors declare that they have no competing interests. 


\section{References}

1. Jemal A, Bray F, Center MM, Ferlay J, Ward E and Forman D: Global Cancer Statistics. CA Cancer J Clin 61: 69-90, 2011.

2. Atherton MJ, Stephenson KB, Pol J, Wang F, Lefebvre C, Stojdl DF, Nikota JK, Dvorkin-Gheva A, Nguyen A, Chen L, et al: Customized viral immunotherapy for HPV-associated cancer. Cancer Immunol Res 5: 847-859, 2017.

3. Dong B, Minze LJ, Xue W and Chen W: Molecular insights into the development of $\mathrm{T}$ cell-based immunotherapy for prostate cancer. Expert Rev Clin Immunol 10: 1547-1557, 2014.

4. Kumai T, Fan A, Harabuchi Y and Celis E: Cancer immunotherapy: Moving forward with peptide T cell vaccines. Curr Opin Immunol 47: 57-63, 2017.

5. Melssen M and Slingluff CL Jr: Vaccines targeting helper T cells for cancer immunotherapy. Curr Opin Immunol 47: 85-92, 2017.

6. Wang P, Li S, Siriwon N, Zhang X, Yang S, Jin T, He F, Kim YJ, Mac J, Lu Z, Wang S, et al: Enhanced cancer immunotherapy by chimeric antigen receptor-modified T Cells engineered to secrete checkpoint inhibitors. Clin Cancer Res 23: 6982-6992, 2017.

7. Simmons G, Bertram S, Glowacka I, Steffen I, Chaipan C, Agudelo J, Lu K, Rennekamp AJ, Hofmann H, Bates P and Pöhlmann S: Different host cell proteases activate the SARS-coronavirus spike-protein for cell-cell and virus-cell fusion. Virology 413: 265-274, 2011.

8. Gao HM, Zhou H, Zhang F, Wilson BC, Kam W and Hong JS: HMGB1 acts on microglia Mac1 to mediate chronic neuroinflammation that drives progressive neurodegeneration. J Neurosci 31: 1081-1092, 2011.

9. Swamydas M, Ricci K, Rego SL and Dréau D: Mesenchymal stem cell-derived CCL-9 and CCL-5 promote mammary tumor cell invasion and the activation of matrix metalloproteinases. Cell Adh Migr 7: 315-324, 2013.

10. Kuo P, Tuong ZK, Teoh SM, Frazer IH, Mattarollo S and Leggatt GR: HPV16E7-induced hyperplasia promotes CXCL9/10 expression and induces CXCR $3^{+}$T-cell migration to skin. J Invest Dermatol S0022-202X: ppi 33358-4, 2017.

11. Matsumoto M, Oshiumi H and Seya T: Antiviral responses induced by the TLR3 pathway. Rev Med Virol 21: 67-77, 2011.

12. Beider K, Abraham M and Peled A: Chemokines and chemokine receptors in stem cell circulation. Front Biosci 13: 6820-6833, 2008.

13. Han K, Zhao T, Chen X, Bian N, Yang T, Ma Q, Cai C, Fan Q, Zhou Y and Ma B: microRNA-194 suppresses osteosarcoma cell proliferation and metastasis in vitro and in vivo by targeting CDH2 and IGF1R. Int J Oncol 45: 1437-1449, 2014.

14. Drouillard A, Puleo F, Bachet JB, Ouazzani S, Calomme A, Demetter P, Verset G, Van Laethem JL and Maréchal R: DLL4 expression is a prognostic marker and may predict gemcitabine benefit in resected pancreatic cancer. Br J Cancer 115: 1245-1252, 2016.

15. Livak KJ and Schmittgen TD: Analysis of relative gene expression data using real-time quantitative PCR and the 2(-Delta Delta C(T)) method. Methods 25: 402-408, 2001.
16. Arnatt CK, Adams JL, Zhang Z, Haney KM, Li G and Zhang Y: Design, syntheses, and characterization of piperzine based chemokine receptor CCR5 antagonists as anti prostate cancer agents. Bioorg Med Chem Lett 24: 2319-2323, 2014.

17. Aaron M, Klein RD, Rengel RC, Clinton SK, Kulp SK, Kashida Y, Yamaguchi M, Wang X and Chen CS: Chemopreventive and bioenergetic signaling effects of PDK1/Akt pathway inhibition in a transgenic mouse model of prostate cancer. Toxicol Pathol 35: 549-561, 2007.

18. Araki S, Omori Y, Lyn D, Singh RK, Meinbach DM, Sandman Y, Lokeshwar VB and Lokeshwar BL: Interleukin-8 is a molecular determinant of androgen independence and progression in prostate cancer. Cancer Res 67: 6854-6862, 2007.

19. Hol J, Wilhelmsen L and Haraldsen G: The murine IL-8 homologues KC, MIP-2, and LIX are found in endothelial cytoplasmic granules but not in weibel-palade bodies. J Leukoc Biol 87: 501-508. 2010.

20. Corbel SY, Merzaban JS, Carlow DA, Gossens K, Duenas J, So L, Yi L and Ziltener HJ: Recruitment of adult thymic progenitors is regulated by P-selectin and its ligand PSGL-1. Nat Immunol 6: 626-634, 2005.

21. Delk NA and Farach-Carson MC: Interleukin-6: A bone marrow stromal cell paracrine signal that induces neuroendocrine differentiation and modulates autophagy in bone metastatic PCa cells. Autophagy 8: 650-663, 2012.

22. Rautava S, Lu L, Nanthakumar NN, Dubert-Ferrandon A and Walker WA: TGF- $\beta 2$ induces maturation of immature human intestinal epithelial cells and inhibits inflammatory cytokine responses induced via the NF- $\kappa \mathrm{B}$ pathway. J Pediatr Gastroenterol Nutr 54: 630-638, 2012.

23. Guo R, Meng Q, Guo H, Xiao L, Yang X, Cui Y and Huang Y: TGF- $\beta 2$ induces epithelial-mesenchymal transition in cultured human lens epithelial cells through activation of the PI3K/Akt/mTOR signaling pathway. Mol Med Rep 13: 1105-1110, 2016.

24. Echeverría C,Montorfano I,Tapia P,Riedel C,Cabello-Verrugio C and Simon F: Endotoxin-induced endothelial fibrosis is dependent on expression of transforming growth factors $\beta 1$ and $\beta 2$. Infect Immun 82: 3678-3686, 2014.

25. Chen H, Sun Y, Wu C, Magyar CE, Li X, Cheng L, Yao JL, Shen S, Osunkoya AO, Liang C and Huang J: Pathogenesis of prostatic small cell caricinma involves the inactivation of the P53 pathway. Endocr Relat Cancer 19: 321-331, 2012.

26. Calzascia T, Pellegrini M, Hall H, Sabbagh L, Ono N, Elford AR, Mak TW and Ohashi PS: TNF-alpha is critical for antitumor but not antiviral $\mathrm{T}$ cell immunity in mice. J Clin Invest 117: 3833-3845, 2007.

(i) $\ominus$ This work is licensed under a Creative Commons cc) Attribution-NonCommercial-NoDerivatives 4.0 International (CC BY-NC-ND 4.0) License. 